\title{
Circuitos cortos de comercialización agroecológica en el Ecuador
}

\author{
Agroecological short circuits of marketing in Ecuador \\ Jackeline Contreras Díaz*1, Myriam Paredes Chauca², Sandra Turbay Ceballos ${ }^{3}$
}

\section{RESUMEN}

Este artículo analiza los factores que fomentan la sostenibilidad de los circuitos cortos de comercialización de la Unión de Organizaciones Productoras Agroecológicas y de Comercialización Asociativa de Tungurahua (PACAT), en Ecuador. Con base en revisión documental, visitas y entrevistas a informantes clave, las autoras encontraron que la viabilidad de esta estrategia económica depende de la fortaleza de las instituciones informales que mantiene la organización social, lo que permite reducir los costos de transacción, mejorando de esta manera la eficiencia económica. Es así que los circuitos cortos de comercialización pueden contribuir al fomento de la producción agroecológica. Adicionalmente, el estudio indica los retos administrativos que las organizaciones enfrentan cuando intentan legalizarce.

Palabras clave: circuitos cortos de comercialización, agroecología, Ecuador, economía popular y solidaria, mercados campesinos.

\begin{abstract}
This article analyzes the factors that promote the sustainability of short circuits of marketing of the Union de Organizaciones Productoras Agroecológicas y de Comercialización Asociativa de Tungurahua (PACAT) in Ecuador. Based on document review, key informant interviews and visits to their farms, the authors found that the viability of this economic strategy depends on the strength of informal institutions that sustain local organization and reduce transaction costs, thereby improving economic efficiency. In this way short circuit marketing can contribute to the proliferation of agro-ecological production. In addition, the study indicates the administrative challenges that informal organizations face when attempting to become formal, legal entities.
\end{abstract}

Key words: short circuits of marketing, agroecology, Ecuador, popular and solidarity economy, farmers markets.

\section{Introducción}

La Constitución de la República del Ecuador (2008) respalda la economía social y solidaria, promueve la soberanía alimentaria y consagra el derecho al acceso seguro y permanente a alimentos sanos, suficientes y nutritivos, producidos preferentemente a nivel local de acuerdo con las distintas identidades y tradiciones culturales del país. Estos principios constitucionales fueron recogidos por la Ley Orgánica del Régimen de la Soberanía Alimentaria (Asamblea Nacional de la República del Ecuador, 2009) y se han aplicado en el Plan de Desarrollo del Ecuador que tiene como objetivo fundamental conseguir el Buen Vivir o Sumay Kawsay, principio que engloba la recuperación de los derechos individuales y colectivos y los derechos de la naturaleza y que para algunos analistas constituye una ruptura con el saber europeo y una expresión de los saberes y sensibilidades propias de América Latina (Gudynas, 2009). La Agricultura Familiar Campesina (AFC) provee el $60 \%$ del total de alimentos consumidos en el Ecuador, es generadora de empleo y utiliza menos cantidad de insumos, por tanto, es una alternativa de manejo sustentable de los recursos (Estrategia

1 Universidad de Antioquia, Medellín Colombia. Pontificia Universidad Católica del Ecuador, Facultad de Economía. Quito, Ecuador.

2 FLACSO Sede Ecuador Departamento de Desarrollo, Ambiente y Territorio. Quito, Ecuador.

3 Universidad de Antioquia, Departamento de Antropología. Sede de Investigación Universitaria. Medellín, Colombia.

* Autor por correspondencia: *yjcontreras@puce.edu.ec 
Nacional para la Igualdad y Erradicación de la Pobreza, 2014). No obstante, su aporte a la soberanía alimentaria y al cuidado del ambiente, es poco el retorno monetario que sus miembros perciben. El $80 \%$ y $85 \%$ de la comercialización campesina pasa por canales de intermediación (Hidalgo, Lacroix y Román, 2013). Como alternativa para que los y las productoras reciban un precio más justo, han surgido canales de comercialización directa entre productores y consumidores, ligados a procesos productivos libres de químicos y con manejo y reciclaje de insumos naturales provistos por las propias fincas, que se encuentran en transición a la agroecología, que han recibido poco apoyo desde la política pública.

Este trabajo pretende aportar al diseño de políticas públicas que fomenten procesos de comercialización alternativa, mediante el análisis de la sostenibilidad de la comercialización de productos agroecológicos emprendido por la Unión de Organizaciones Productoras Agroecológicas y de Comercialización Asociativa de Tungurahua (PACAT) en el Ecuador. El análisis de los circuitos cortos de comercialización se hace aquí desde una perspectiva institucional toda vez que este tipo de iniciativas para el desarrollo rural exige un reajuste de las instituciones formales e informales para poder acercar a productores y consumidores (Rosas y Barkin, 2009). PACAT opera desde el 2004 y es una organización que aglutina a 35 organizaciones de pequeños productores agroecológicos de los nueve cantones de la provincia de Tungurahua. En el 2010 esta organización tenía 508 socios activos, la mitad de ellos indígenas, que producían y comercializaban hortalizas, legumbres, granos tiernos, tubérculos, frutas, plantas medicinales, condimentos, productos cárnicos, huevos y derivados de la leche. La comercialización de productos en la Plaza Pachano de Ambato comenzó en el 2006 con 18 productores; en el 2014 ya eran 100 los que ofrecían cada sábado sus productos en la plaza (entrevistas a técnicos PACAT, 2014).

\section{Circuitos cortos de comercialización agroecológica}

Los circuitos cortos de comercialización agroecológica surgen como redes alternativas de comercialización en mercados locales y configuran un modelo de circulación sostenible desde el punto de vista ecológico y social.
Toda vez que la agroecología como ciencia en construcción concibe un marco amplio de análisis de los procesos agrícolas, cuya orientación es transformar a la agricultura en una actividad más sustentable y productiva, para mejorar la vida de los productores agrícolas que trabajan en pequeñas parcelas y tierras marginales, con estrategias de subsistencia ecológicamente sensibles, con la promoción de tecnologías de bajo insumo y costo y con la promoción de empleos, que aumenten el valor agregado de lo que se produce (Altieri y Nicholls, 2000).

Binimelis y Descombes definen como criterios centrales para abordar el estudio de los circuitos: proximidad, relación, información, participación, inclusión y sostenibilidad social (2010). Desde este punto de vista, los circuitos cortos de comercialización son parte de iniciativas que transforman el mercado en un medio para el desarrollo más que en un fin en sí mismo. Desde la experiencia del Ecuador, Chauveau y Taipe (2012) los circuitos cortos alternativos abarcan una variedad de productos a diferencia de la cadena de producción de un solo producto. El adjetivo 'cortos' describe la relación directa entre productor y consumidor o los representantes de cada grupo, en tanto que 'alternativos' se refiere a los objetivos distintos que persiguen los actores organizados y que hacen referencia a la soberanía alimentaria, al empoderamiento de familias, a la sostenibilidad económica y ambiental en los territorios rurales y al fomento de relaciones más equitativas entre campo y ciudad (2012). Este tipo de comercialización se expresa en ferias campesinas, tiendas de productos campesinos, canastas de consumidores, compras públicas por parte del Estado y mercados internacionales de comercio justo.

En este estudio se considera los circuitos cortos de comercialización como redes alternativas al mercado común en las que existen relaciones directas entre productores y consumidores que comparten información y ciertos valores. Estas conexiones contribuyen a la soberanía alimentaria porque implican atención no solo al proceso de circulación de los productos sino a su producción y reproducción. En consecuencia, el estudio se concentra tanto en las ferias campesinas como mecanismo de distribución como en la incidencia de estas en los procesos de transición a la agroecología. En este orden de ideas, los circuitos cortos de 
comercialización no son simplemente económicos, sino que están imbricados en el conjunto de la vida social. La economía neoinstitucional toma en cuenta lo anterior e incorpora en el análisis económico a las instituciones como factores determinantes del desarrollo (Téllez y Cubillos, 2009). Además, presta atención a los costos de transacción (North, 1993 citado por Alazea y Mercado 2011). Ya Hobbs (1997) había propuesto un análisis de la transacción que incluía los costos anteriores a la misma transacción, durante y posteriores a ella. Esta propuesta es retomada por Williamson (2000), quien señala cinco determinantes de los costos de transacción:

1. La frecuencia de la transacción que construye confianza y reduce los costos de monitoreo. 2. La especificidad de los activos. Se refiere en este caso a los cultivos y al tiempo necesario para que lo sembrado pueda ser cosechado, es decir, que lo invertido pueda retornar. 3 . La incertidumbre en el proceso de intercambio. A mayor incertidumbre en las condiciones de intercambio más complejidad en los contratos y más tensión entre los actores del mercado. 4. La racionalidad limitada. Por tanto, se trata de aumentar los costos de negociación y monitoreo en un esfuerzo por disminuir la incertidumbre. 5. El comportamiento oportunista que se presenta frente a la división de recursos escasos, lo que lleva a la necesidad de crear instituciones que garanticen el control, monitoreo y aplicación de garantías o ejecución de las mismas, lo que, a su vez, lleva a subir los costos de transacción (Hobbs, 1997).

\section{Métodos}

Este estudio utilizó una metodología cualitativa de investigación y se articuló alrededor de categorías centrales como la sostenibilidad, las instituciones y el capital social comunitario. Durante la primera fase, se realizó un mapa de actores y posteriormente se realizaron diez entrevistas semiestructuradas a representantes de las instituciones que han participado en la construcción de estos circuitos desde el inicio. Se revisaron documentos en los archivos de la PACAT con el fin de reconstruir su historia e identificar sus objetivos. Más adelante, se entrevistaron a profundidad 12 socios de la PACAT identificados con la ayuda de los directivos y, durante los días que se observó la feria de la PACAT (Feria Plaza Pachano) se realizaron también consultas con las socias que participan en la venta. Al mismo tiempo, una de las autoras participó en tres reuniones de los socios y en cinco grupos focales con directivos y socios. Las entrevistas y las reuniones fueron grabadas y transcritas. En diez oportunidades se observó la dinámica de la feria que se desarrolla cada sábado en la ciudad de Ambato, las observaciones quedaron consignadas en un diario de campo. Asimismo se han visitado alrededor de cinco fincas en las tres zonas ecológicas en donde hay socios de PACAT y se pudo participar en las rutinas cotidianas de trabajo de las fincas.

\section{Resultados y Discusión}

Este estudio detectó cinco factores principales que contribuyen a la sostenibilidad de los circuitos cortos de comercialización de la PACAT y que se tratan a continuación:

\section{Una economía regional dinámica}

La experiencia de PACAT se desenvuelve en la provincia de Tungurahua que se ubica en la Sierra Central (ver Figura 1). La provincia tiene una dinámica comercial que explica por qué los pequeños comerciantes y los emprendedores tienen allí mayor empoderamiento que en el resto de las provincias del Ecuador (RIMISP, 2011). A la diversificada oferta de productos agrícolas que hay en Tungurahua, se agrega la existencia de una red de 60 ferias semanales en 19 sitios distintos donde se venden alimentos, animales menores, flores, frutas y ganado. La capital Ambato constituye el centro de esa red de ferias y el lugar de acopio de productos que abastecen los mercados de Quito, de Guayaquil y de otras ciudades del país (RIMISP, 2011). En Tungurahua existen 201.905 ha de suelo distribuidas en 71.317 unidades productivas agrícolas (UPA). Las fincas medianas, que comprenden el $1 \%$ de las fincas, ocupan el $13 \%$ de la superficie agropecuaria y su extensión promedio es de 41 ha. Las explotaciones agrícolas mayores a 100 ha representan apenas el 0,2\% de las fincas y ocupan el $43 \%$ de la superficie con una extensión promedio de 594 ha por hacienda. Entre tanto, las fincas menores de 20 ha, que constituyen el $99 \%$ de las unidades productivas, ocupan el $44 \%$ de la superficie con un tamaño promedio por finca de 1,3 ha. A este grupo de fincas pertenecen 


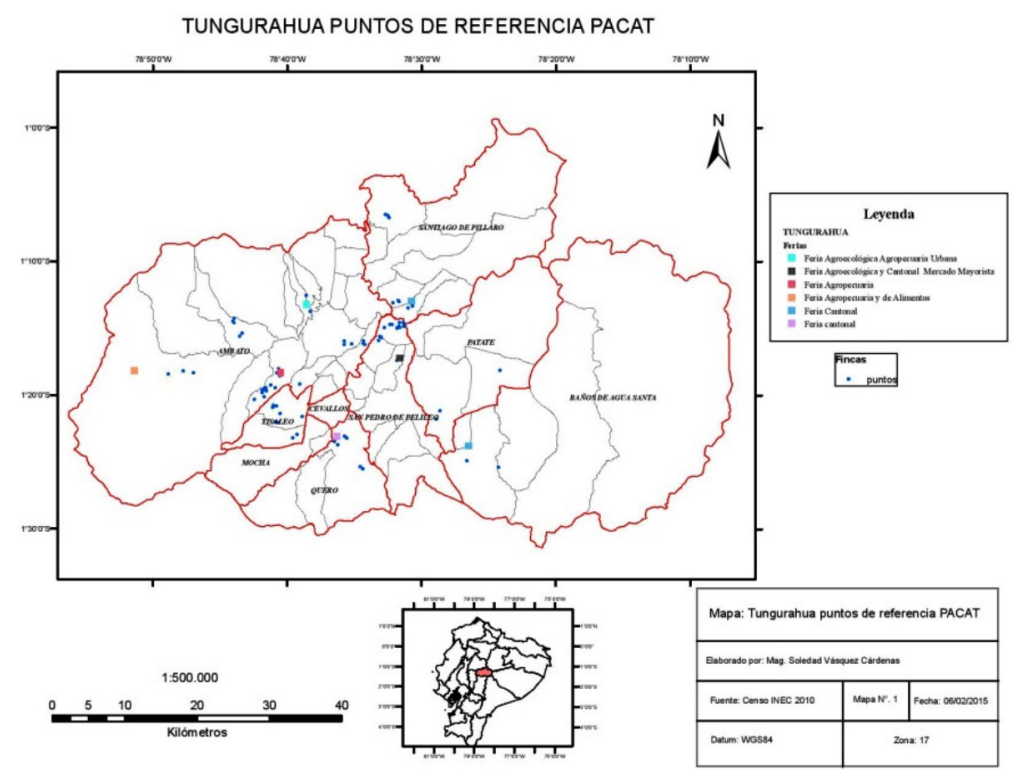

Figura 1. Describe el mapa de la provincia de Tungurahua que se ubica en la Sierra Central del Ecuador que se señala con rosado en la parte inferior de la figura.

los y las socias de PACAT. Los miembros de PACAT se asientan en tres zonas productivas que corresponden a diferentes pisos climáticos, condiciones del suelo y formas de producción y organización, lo que plantea tanto retos como también procesos de complementariedad. En la zona alta, que está entre los 3.050 y los $4.000 \mathrm{msnm}$ hay 14 organizaciones; en la media, que está entre los 2.500 y $3.050 \mathrm{msnm}$ hay 18 organizaciones y en la zona baja, localizada entre los 2.000 y los $2.5000 \mathrm{msnm}$, hay cuatro organizaciones. El $40 \%$ de las unidades productivas agrícolas no cuentan con riego y están ubicadas en la zona alta, poblada por grupos indígenas (Bustos, 2010, entrevistas técnicos PACAT, 2013). Los asociados son, en su mayoría, propietarios de varios lotes de tierra que han heredado o que han comprado a sus parientes o vecinos. Las unidades productivas agrícolas de los socios de la PACAT tienen una extensión que oscila entre $857 \mathrm{~m}^{2}$ y $10.000 \mathrm{~m}^{2}$, siendo la extensión promedio de $3.528 \mathrm{~m}^{2}$ (Bustos, 2010). El estrés hídrico, la insuficiencia de los sistemas de riego y el mal estado de las redes secundarias ha hecho que las organizaciones filiales de la PACAT participen activamente en las 266 juntas de riego de la provincia que administran el agua de acuerdo a la disponibilidad estacional del recurso y a los turnos establecidos (Gobierno Provincial de Tungurahua, 2011).

\section{Un nuevo modelo de gestión local}

La experiencia de la PACAT se desenvuelve dentro de un proceso de gestión que inició el prefecto provincial en el 2005, caracterizado por la creación de espacios de concertación de la inversión pública, la promoción de la participación ciudadana y la coordinación interinstitucional para crear sinergias. La Estrategia Agropecuaria de Tungurahua incluye propuestas alrededor de nueve líneas estratégicas: capacitación y asistencia técnica, fortalecimiento socio-empresarial, producción agroecológica, tecnificación de riesgo, comercialización y agroindustria, manejo de riesgos agropecuarios, manejo de recursos naturales, agroturismo comunitario y crédito agropecuario (Gobierno Provincial de Tungurahua, 2011). La sostenibilidad lograda en el modelo de comercialización de la PACAT se debe al apoyo permanente a la PACAT mediante la inclusión y desarrollo de una línea agroecológica en la Estrategia Agropecuaria de Tungurahua, lo que ha permitido la contratación y pago permanente de técnicos que asesoran a los productores, a la asamblea general, a los coordinadores y a las comisiones permanentes. Los miembros más antiguos de la PACAT indicaron durante las entrevistas que ellos conocían el trabajo de la tierra desde su niñez, pero que las capacitaciones que recibieron y los aportes que les 
transmitieron agricultores de otros lugares, les han sido de mucha utilidad para mejorar sus prácticas agrícolas y pecuarias y solucionar problemas en la finca. Además, sienten ahora más autoestima por el reconocimiento que reciben de las personas que visitan sus fincas con el fin de conocer sus experiencias en la producción agroecológica.

Los esfuerzos del gobierno provincial se han visto complementados por la disposición de los centros académicos, como la Universidad Técnica de Ambato, para establecer un intercambio de saberes con los socios de la PACAT. Los académicos asesoran con técnicas nuevas a los productores y ellos adecuan estos conocimientos a sus propias situaciones para lo que utilizan sus sabiduría ancestrales de producción, por ejemplo, en la asociación de cultivos o en el manejo de abonos orgánicos. Esto se ha expresado en un acompañamiento a las familias campesinas que hacen experimentos en sus fincas y que van consolidando poco a poco un saber agroecológico localizado.

Como resultado de esta articulación se creó una Unidad de Certificación Agricultura Limpia que funciona en la Facultad de Agronomía de la Universidad Técnica de Ambato. Paralelamente, y mediante un decreto, se declaró la provincia de Tungurahua como territorio de agricultura limpia. Agricultura limpia hace alusión al proceso productivo que garantiza que los productos de consumo humano cumplan con requisitos mínimos de inocuidad y establece un espacio de confianza del consumidor en la calidad del producto (Unidad de Certificación Agricultura Limpia Tungurahua, 2011). Este calificativo, señala el compromiso de los productores en persistir en los procesos de agricultura limpia de químicos como medio para profundizar la transición agroecológica. Alrededor de cien socios de la PACAT cuentan ya con una certificación y el consejo directivo promueve que más socios puedan obtenerla, sin detrimento de aquellos que tienen procesos locales de veeduría para garantizar la calidad agroecológica del producto que se comercializa. En suma, el éxito de la sostenibilidad de los circuitos cortos de comercialización de la PACAT se debe, en parte, a la confluencia en el territorio provincial de Tungurahua, de un modelo de gestión pública local verdaderamente innovador y de políticas nacionales que privilegian la búsqueda del buen vivir en distintas escalas territoriales.

\section{Además de un entorno favorable, una organización que nos protege}

La Unión de Organizaciones Productoras Agroecológicas y de Comercialización Asociativa, "PACAT", se constituyó en diciembre del 2006 como una filial de los Movimientos Indígenas de Tungurahua. En sus estatutos se plantean como propósito general la búsqueda del bienestar y la asistencia en situaciones de calamidad de sus socios y, como propósitos específicos, la promoción de la producción agroecológica, la comercialización asociativa, el rescate de las tecnologías ancestrales de producción, el apoyo económico a los socios por medio de una caja de ahorro y crédito, el correcto manejo de los recursos naturales, el desarrollo de la seguridad alimentaria y la búsqueda de precios justos para productores y consumidores (art 2 Estatutos PACAT). Los socios entrevistados resaltan como uno de los principales logros de la PACAT el haber obtenido un espacio de mercado común para la venta de productos excedentes: "antes teníamos que ir al [mercado] mayorista y entregar nuestros productos por la mitad o menos de lo que recibimos ahora", dice uno de los socios. En otros casos, el intermediario visitaba las fincas y vendían el producto en la huerta, aún sin cosechar, lo que representaba un ahorro de trabajo considerable, pero disminuía las utilidades para el productor.

Cada una de las 35 organizaciones que aglutina PACAT tiene sus particularidades, unas están más enfocadas a la piscicultura, otras a la producción agrícola, otras al agroecoturismo, algunas están conformadas exclusivamente por mujeres, etc. Los socios de PACAT coinciden en que el pertenecer a la organización les favorece y permite que su actividad agrícola, pecuaria tenga un apoyo. La estructura organizativa de PACAT es un buen ejemplo de un capital social comunitario que se ha mantenido por años y se ha trasmitido de generación a generación, lo que se trata con mayor detalle en el siguiente acápite. Sin embargo, en la actualidad la sostenibilidad de los circuitos cortos de comercialización está amenazada por el proceso de regulación de la Economía Popular y Solidaria mediante la ley de Economía Popular y Solidaria del 2012 y su Reglamento. El proceso obliga al registro y regulación de las organizaciones en la Superintendencia de Economía Popular y Solidaria, lo que implica una actualización de la legalización, una revisión de los estatutos de las 
organizaciones, un registro de la directiva, y la tramitación de un permiso de funcionamiento. Lo que es más complejo, las asociaciones deben rendir balances anuales debidamente sustentados, que sirven de base para determinar la carga impositiva que deben entregar al gobierno.

La actualización del registro de las asociaciones filiales constituye un problema, ya que supone pagar en un solo monto los valores que por registro y funcionamiento debieron haber cancelado anualmente desde la legalización de las asociaciones. Esta suma que puede oscilar entre 1.000 y 1.500 dólares, es difícil de cubrir para muchas asociaciones pequeñas que se han visto obligadas a enfrentar procesos de liquidación.

El resultado general del proceso de legalización y las dificultades enfrentadas por las organizaciones filiales de la PACAT ha llevado a que en septiembre del 2014 solo el 37\% de las asociaciones estén registradas en la Superintendencia de Economía Popular y Solidaria. Los directivos de PACAT frente a la situación descrita han precautelado la permanencia de la Unión, para ello cambiaron sus estatutos y los adecuaron de manera que ahora solo figuran como Unión de Productores Agroecológicos. Sin embargo, como era indispensable que PACAT legalizara las actividades de comercialización, creó una empresa de hecho dedicada a la comercialización mediante la que están funcionando. Algunas de las asociaciones registradas han sido sujeto ya de revisión por parte de la Superintendencia. De acuerdo con uno de los representantes de una de las asociaciones supervisadas, cuando los funcionarios encontraron balances que no registraban ganancias reclamaron: "tienen que ser una empresa, sino tienen ganancia, ¿para qué se asocian?" Por su parte, las asociaciones registradas tampoco conocen si el registro con balances sin ganancias va a tener algún propósito concreto en sus planes futuros $y$, a diferencia de las cooperativas de ahorro y crédito que subieron las tasas de interés de los créditos a partir de su registro en la Superintendencia, las asociaciones que son parte de PACAT, no han trasladado los costos del proceso al grupo de consumidores que compra en la plaza Pachano.

\section{Ayudas y acuerdos para que funcione el mercado: reproduciendo el capital social}

La feria de la PACAT surgió por la necesidad que tenían las familias asociadas de comercializar el excedente que se presentaba después de que la familia consumiera la producción agroecológica de la finca. Aunque la vinculación a los mercados no les era totalmente ajena, la creación de un mercado agroecológico con venta directa a los consumidores significó un reto. En el 2006 se inició la venta en la feria de la plaza Pachano los días sábados. Los agricultores pagan una suma semanal que sirve para que la PACAT cumpla con los impuestos que cobra la autoridad por el uso del lugar, pero que también se invierten en mejoras como la construcción de estanterías. Los espacios se comparten entre familias que son parte de una misma asociación y que se hacen presentes en la feria siguiendo turnos preestablecidos. Si algún productor apenas tiene uno o dos productos para ofrecer el día que le corresponde, puede llamar a otro miembro de su asociación para que lo reemplace. Las vendedoras de un mismo puesto no solamente son miembros de la misma organización, sino que son amigas que se prestan múltiples servicios, por ejemplo, las mujeres dejan a alguien encargado del puesto mientras se movilizan por la plaza, o las vendedoras intercambian o compran productos dentro de la misma plaza para que sus clientes puedan llevar todo lo que necesitan. La entrega de una yapa o regalo adicional a la compra o al intercambio, es una práctica relacionada con la calidad de la relación entre las personas involucradas en la transacción y contribuye a reforzar los lazos con las compañeras de trabajo, que a veces son comadres, y a garantizar la fidelidad de los clientes.

Las relaciones de reciprocidad se extienden a las personas que prestan el servicio de transporte en la madrugada, pues no se limitan a recoger a quienes han contratado el servicio en forma conjunta para abaratar costos, sino que les ayudan a cargar y a descargar los productos. Los acuerdos en materia de transporte se repiten semana a semana respetando acuerdos establecidos sobre lugares, horas y precios. Contar con un puesto de venta en la plaza significa disponer también de una red de relaciones sociales que se activa cuando hay problemas con la salud de los cultivos o cuando se necesita "prestar una mano" para atender las tareas agrícolas. En la zona centro, por ejemplo, los socios y socias de PACAT destinan un día para ayudar a sus compañeros en el trabajo del campo, lo que es muy significativo teniendo en cuenta que muchos de ellos son adultos mayores y que es difícil contratar mano de obra en la zona por escasez de personal o de recursos. 
El hecho de pertenecer a la PACAT da también la posibilidad de acceder a un crédito para la compra de insumos agrícolas o para el mejoramiento de la infraestructura de la finca, basta con estar al día en sus obligaciones y firmar un pagaré. Los mecanismos descritos son expresiones del capital social comunitario que ha permitido que los circuitos cortos de comercialización se mantengan.

En el funcionamiento de la feria de la PACAT también se revelan los criterios de proximidad entre compradores y vendedores, relación entre ellos, lo que permite trasmisión de información, elementos que fueron mencionados por Binimelis y Descombes (2010) como centrales para abordar el estudio de los circuitos cortos de comercialización.

La sostenibilidad de los circuitos cortos de comercialización no podría ser realidad sin una oferta de productos permanente, lo que se ha logrado con siembras semanales planificadas para escalonar la producción y disponer siempre de productos para ofrecer en el mercado. Esta oferta tiene como condición esencial la producción agroecológica y limpia de químicos, auditada por los directivos y formalizada por medio de una certificación, obtenida cada vez por más agricultores. Los socios que no alcanzan a vender toda la producción en la feria Pachano el día sábado suelen buscar otros canales de venta directa al consumidor, como la feria de Huachi, parroquia cercana a Ambato, que se celebra el día domingo. También se entregan productos en restaurantes de Ambato y a una tienda especializada de productos orgánicos en Guayaquil, aunque estos dos canales de distribución todavía son incipientes. El pertenecer a PACAT no impide a los socios que tengan una producción más grande y acudir a la plaza del mercado mayorista de Ambato los días lunes, siempre y cuando satisfaga las obligaciones que tiene con el puesto de la Pachano. La proporción de producto que se vende en la plaza Pachano, depende de la cantidad de tierra cultivada por el/la productora, de la estación del año y de las predicciones de venta que haya hecho el/la productora, entonces puede variar del $10 \%$ al $60 \%$ de la producción luego de haber descontado la parte dedicada al autoconsumo.

\section{Cuesta menos vender}

La motivación mayor para la formación de PACAT ha sido la venta directa a los consumidores lo que resulta más beneficioso, porque ellos obtienen más por sus productos y les cuesta menos vender. Los circuitos cortos de comercialización de la PACAT presentan de forma específica los determinantes de los costos de transacción que señala Williamson (2000): frecuencia, especificidad de los activos, manejo de la incertidumbre, racionalidad limitada y control del comportamiento oportunista.

Así, gracias a la permanencia de la feria de la plaza Pachano, existe una frecuencia de las transacciones que asegura a los productores que puedan vender la totalidad de sus productos. Esto significa un flujo permanente de recursos cada semana, no solo en dinero sino en productos obtenidos por medio del intercambio, lo que ayuda a completar y diversificar la canasta básica de alimentos y posibilita que se reduzca el costo por alimentación semanal, esta reducción podría estimarse entre el 30 y el $50 \%$ del costo semanal. Los/ las productoras tienen su clientela fija, entre los que se han creado lazos de amistad y confianza frente a la calidad de lo que se ofrece y se compra, lo que reduce costos de monitoreo (Williamson, 2000). Es decir, tanto productores como consumidores cuentan el uno con el otro, no es necesario un tercero para que las transacciones se realicen.

Otro determinante de los costos de transacción a considerar es el tiempo necesario para que lo sembrado pueda ser cosechado, es decir, que lo invertido pueda retornar (Williamson, 2000). En el caso de la PACAT, existe una especialización por las hortalizas de ciclo corto, cuya inversión requiere un tiempo de tres meses desde la siembra a la cosecha. La sostenibilidad de estos ciclos de producción, se asientan en el apoyo financiero de la organización para la compra de semillas, la preparación del suelo y plántulas. Las y los productores que acceden a estos beneficios hacen pagos flexibles, a tasas de interés cómodas.

Un tercer determinante de los costos de transacción es la incertidumbre en el proceso de intercambio. A mayor incertidumbre en las condiciones de intercambio más complejidad en los contratos y más tensiones para los actores en el mercado (Williamson, 2000). En el caso de PACAT, la mayor incertidumbre que tienen los/las productoras es la propia competencia que pueden tener entre los y las propias socias que venden en la plaza Pachano. Si bien la estacionalidad de ciertos productos hace que ciertas etapas del año, 
se cuente con mayor disponibilidad de un tipo de producto, la siembra escalonada de los cultivos entre los/las productoras y un acuerdo acerca de lo que se ofrece en la plaza, ha favorecido para que cada socio tenga certidumbre sobre la venta. Así en una entrevista y visita a una finca el productor señalaba que vendía fresas y aunque en su finca había otros productos, decía "no esto no lo vendo en la Pachano sino en otras partes". Los acuerdos respecto de lo que se ofrece garantizan también que el volumen ofrecido se venda totalmente.

Un cuarto elemento que determina los costos de transacción es la racionalidad limitada, que alude a que los actores conocen o pueden predecir. Por tanto, se trata de aumentar los costos de negociación y monitoreo en un esfuerzo por disminuir la incertidumbre (Williamson, 2000). En los circuitos cortos de comercialización de la PACAT dada la relación de confianza y cercanía entre productores y consumidores, ambos comparten las situaciones imprevistas en los procesos productivos y los costos que ello origina, por ejemplo, si no hay disponibilidad de un producto, debido a plagas o condiciones extremas de sequía o de inundación, el precio del producto en el mercado sube o bien se reduce la cantidad ofertada por el mismo precio. Las yapas o regalos de productos extra tienen aquí la función de ofrecer una compensación a sus clientes con otros productos y de esta manera evitan perder al cliente o que aumente su grado de incertidumbre para conseguir vender lo ofertado.

Un elemento adicional que determina los costos de transacción es el comportamiento oportunista que se presenta frente a la división de recursos escasos, lo cual lleva a la necesidad de crear instituciones que garanticen el control, monitoreo y aplicación de garantías o ejecución de las mismas, lo que, a su vez, lleva a subir los costos de transacción (Williamson, 2000). Uno de los desafíos de PACAT es evitar que productores/as que no son agroecológicos vendan sus productos en la plaza Pachano. Si bien la certificación del proceso de agricultura limpia ha favorecido para que los productos que se vendan sean agroecológicos, el costo del proceso de certificación y la falta de supervisión permanente ha hecho que exista un comportamiento oportunista de algunos de los socios/as. En suma, la reducción de los costos de transacción es determinante para la sostenibilidad de los circuitos cortos de comercialización de la PACAT.

\section{Las mujeres vendemos en la Pachano}

Las mujeres de Tungurahua en el 2001 tenían una participación del $38,8 \%$ en el PEA, mientras el promedio nacional se situaba en el 30\% (RIMISP, 2011). Las mujeres constituyen el 98\% de los vendedores en la plaza Pachano. De cada diez socios de PACAT ocho son mujeres y dos son hombres. La capacitación que recibieron fue definitiva, como dicen ellas, "para perder el miedo", "aprender a hablar y negociar con los clientes", "mejorar la presentación y la higiene de los puestos", cumplir con los horarios y adecuar su presentación personal a su nuevo papel como vendedoras. Asistir a la plaza el sábado supone para ellas un gran esfuerzo, dadas sus múltiples ocupaciones. Sin embargo, luchan por cumplir con las demandas de la PACAT, con la ilusión de que algún día sus hijas puedan heredar el puesto en la plaza. Este trabajo en la plaza les ha permitido manejar su propio dinero, les ha dado autonomía en la toma de decisiones económicas, ha incrementado su autoestima y les ha permitido tener muchas amigas con quienes intercambiar chistes y preocupaciones (información de grupos focales y entrevistas, 2014). Las socias son productoras y vendedoras, adicionalmente son las que más créditos han solicitado de los fondos de ayuda de la organización, de acuerdo con el registro ellas realizan el pago completo de los créditos y el destino que tiene el dinero está centrado en el proceso productivo, sea para semillas, compra de animales, que como se conoce, es un ahorro importante en el medio rural. A pesar del protagonismo de las mujeres en todas las actividades de la PACAT, son pocas las que han sido parte de la directiva de la organización. En la actualidad de un directorio de diez personas solo una es mujer. En entrevistas se devela que ellas no han tenido la oportunidad de participar en la toma de decisiones y tampoco ha existido un espacio para que puedan conversar de sus necesidades propias. La plaza Pachano es el espacio donde ellas pueden expresarse y las actividades de mercadeo son las que en mayor medida permiten su empoderamiento social y económico.

\section{Conclusiones}

Los circuitos cortos de comercialización constituyen un factor decisivo en el éxito de 
la experiencia agroecológica de la PACAT. La comercialización directa en la plaza Pachano ha permitido que el trabajo agrícola y pecuario de los socios sea revalorizado, que persista su decisión de producir bajo los principios de la agroecología, que reduzcan los costos de transacción, que reciban capacitación, que puedan acceder al crédito, y que adquieran protagonismo político mediante la integración con otras organizaciones de productores y con instituciones estatales locales, lo que no era posible cuando cada uno de ellos entregaba individualmente sus productos al comerciante mayorista. La sostenibilidad de los circuitos cortos de comercialización se consigue con una oferta permanente de productos agroecológicos, cultivados en forma escalonada por cada socio, la oferta de productos agroecológicos tiene cada vez mayor confiabilidad, debido al proceso de agricultura limpia de químicos, auditada por los directivos y formalizada a través de una certificación, obtenida cada vez por más agricultores. Debido a la importancia de los técnicos, contratados por el Consejo Provincial, en la vida institucional de la organización, ellos se convierten en un puente entre la PACAT y otras instituciones locales, nacionales e incluso internacionales, cuando se trata de proyectos de cooperación y son, en consecuencia, un factor fundamental de la sostenibilidad institucional de los circuitos cortos de comercialización.

Los circuitos cortos de comercialización de la PACAT testimonian la sobrevivencia del capital social comunitario, evidenciado en relaciones recíprocas y solidarias guiadas por una lógica distinta al lucro. No estamos ante un sistema de mercado sino ante un continuo de situaciones empíricas donde, como dice Narotzky (2004) el principio de mercado es más o menos dominante o periférico. Las decisiones sobre qué producir y cuánto producir no están determinadas exclusivamente por la relación entre la oferta y la demanda. La economía campesina no busca la acumulación de capital sino la reproducción del grupo familiar y del proceso de producción de acuerdo con los estándares de calidad de vida establecidos por la cultura local. Los miembros de PACAT producen alimentos para su familia $\mathrm{y}$, con los excedentes que comercializan en Ambato, adquieren bienes y servicios que no producen en sus fincas. La comercialización ha ido ganando protagonismo como mecanismo que permite la reproducción social, entendida no como reproducción de la vida sino del entramado social característico de la región. Debido a la variedad de condiciones de los socios de la PACAT, se puede decir que para algunos, el mercado de la plaza Pachano sigue siendo periférico, porque tienen un alto autoconsumo, mientras que para otros, el porcentaje de la producción de la finca destinado al mercado es mayor hasta el punto de no ser absorbido completamente por el mercado de la plaza Pachano y tener que acudir simultáneamente a la plaza mayorista.

La sostenibilidad de estos circuitos cortos de comercialización se asienta igualmente acerca de una política deliberada de fortalecer la soberanía alimentaria de los socios de la PACAT. La revalorización del conocimiento ancestral que propone la producción agroecológica y la permanencia durante diez años de estos circuitos cortos de comercialización, ha supuesto mayor independencia de los/as socias del mercado de semillas e insumos comercializados por las compañías multinacionales, una disminución del porcentaje de la canasta familiar destinado a la compra de alimentos y un mayor consumo de alimentos producidos localmente. La reducción de los costos de transacción (en arreglos de transporte, mejor precio en la venta del producto, posibilidad de hacer intercambios de producto) es un elemento central de la sostenibilidad de los circuitos cortos de comercialización, y confirma que ellos son un mecanismo importante para el fortalecimiento de la soberanía alimentaria en los territorios, no solo porque se asienta en el capital social comunitario sino porque además permite que productores/as pueden contar con beneficios más justos de la venta de sus productos.

\section{Literatura Citada}

Alazea, R. y Mercado, P.

2011. Presencia de las instituciones en los enfoques del institucionalismo económico: convergencias y divergencias. Revista CS, 8: 83-107.
Altieri, M. y Nicholls, C.I.

2000. Agroecología: teoría y práctica para una agricultura sustentable. México: Programa de las Naciones Unidas para el Medio Ambiente Red de Formación Ambiental 
para América Latina y el Caribe. México D.F., México. $250 \mathrm{p}$.

Asamblea Nacional del Ecuador

2008. Constitución de la República del Ecuador. Quito, Ecuador. 223 p.

Asamblea Nacional de la República del Ecuador

2009. Ley Orgánica del Régimen de la Soberanía Alimentaria. Registro Oficial Suplemento 583. Quito, Ecuador, 23 p.

Blanc, J. y Kledal, P.R.

2012. The Brazilian organic food sector: Prospects and constraints of facilitating the inclusion of smallholders. Journal of Rural Studies, 28 (1): 142-154.

Binimelis, R. y Descombes, C.A.

2010. Comercialització en circuits curts: Identificació i tipologia. Escola Agrària de Manresa i Verloc. Barcelona, España, 63 p.

Bustos, B.

2010. Asociación de Productores Agroecológicos de Comercio Asociativo de Tungurahua (PACAT). En: Bustos, B. and Bustos, H. (compiladoras). Hacia la soberanía alimentaria. Agroecología y comercio asociativo desde experiencias andino-amazónicas. Universidad Andina Simón BolívarEdiciones La Tierra y GTZ. Quito, Ecuador, 89-128 pp.

Chauveau, C. y Taipe, D.

2012. Circuitos alternativos de comercialización. Estrategias de la agricultura familiar campesina. Inventario, impacto, propuesta. Ministerio de Agricultura, Ganadería, Acuacultura y Pesca de Ecuador. Quito, Ecuador, 83 p.

Gobierno Provincial de Tungurahua

2011. Estrategia Agropecuaria Tungurahua. Juntos por una producción limpia para una población sana. Avances 2007-2011; Proyecciones Julio 2011-Dic. 2013. Gobierno Provincial de Tungurahua. GIZ. Ambato Ecuador, 127 p.
Gudynas, E.

2009. La dimensión ecológica del Buen Vivir: entre el fantasma de la modernidad y el desafío Biocéntrico. Centro de Investigación y Promoción Franciscano y Ecológico. Montevideo, Uruguay.

Hidalgo, F., Lacroix, P. y Román, P.

2013. Comercialización Soberanía Alimentaria. SIPAE/ AVSF. Quito, Ecuador, 145 p.

Hobbs, J.E.

1997. Measuring the Importance of Transaction Costs in Cattle Marketing. American Journal of Agricultural Economics, 79 (4): 1083-1095.

RIMISP

2011. Tungurahua rural: el territorio de senderos que se bifurcan. Documento de Trabajo $N^{\circ} 70$ Programa Dinámicas Territoriales Rurales. RIMISP. Santiago, Chile: 46 p.

Rosas, M. y Barkin, D.

2009. Racionalidades alternas en la teoría económica. Economía: teoría y práctica, (31): 73-96.

Secretaría Técnica para la Erradicación de la Pobreza. 2014. Estrategia Nacional para la Igualdad y Erradicación de la Pobreza. SENPLADES, Quito, Ecuador, 258 p.

Téllez, G. y Cubillos, A.

2009. Relaciones entre enfoque neo-institucional, desarrollo y medio ambiente. Opera, 9 (9): 223-239.

Unidad de Certificación Agricultura Limpia Tungurahua 2011. Normativa Agricultura Limpia Tungurahua. Universidad Técnica de Ambato. Ambato, Ecuador, 41 p.

Williamson, O.E.

2000. The New Institutional Economics: Taking Stock, Looking Ahead. Journal of Economic Literature, 38, 595-613. 